\title{
Fidelidade inexorável: Blanchot, Heidegger e Derrida
}

\author{
Inexorable fidelity: Blanchot, Heidegger e Derrida \\ Kelvin Falcão Klein \\ Universidade Federal do Estado do Rio de Janeiro - Rio de Janeiro - Rio de Janeiro - Brasil
}

$\diamond$

\begin{abstract}
Resumo: Partindo de uma carta pessoal, enviada por Maurice Blanchot a Jacques Derrida, este ensaio procura rastrear os temas da correspondência, da distância e da transmissão de ideias no pensamento crítico contemporâneo. Argumenta, além disso, que a troca de cartas constitui já um ramo da filosofia - como atestam os trabalhos de Martin Heidegger, Peter Sloterdijk e Jacques Derrida analisados no texto. Todo esse cenário se desenvolve, desde as linhas iniciais, sob o signo da reflexão blanchotiana a respeito da leitura do tempo e da tradição. Tal reflexão ecoa, finalmente, em uma teoria da comunidade como espaço de debate e de mobilidade epistemológica.
\end{abstract}

Palavras-chave: Filosofia; Crítica literária; Humanismo; Maurice Blanchot; Jacques Derrida

\begin{abstract}
Starting with a personal letter, sent by Maurice Blanchot to Jacques Derrida, this essay attempts to track the topics of correspondence, distance and transmission of ideas in the contemporary critical thought. It also argues that the exchange of letters is now a branch of Philosophy - as demonstrated by the works of Martin Heidegger, Jacques Derrida and Peter Sloterdijk examined in the text. This whole scenario unfolds, since its opening lines, under the sign of Blanchotian thought about reading of time and tradition. Such reflection echoes finally in a theory of community conceived as a space for debate and epistemological mobility.
\end{abstract}

Keywords: Philosophy; Literary criticism; Humanism; Maurice Blanchot; Jacques Derrida

\section{Introdução}

No sexto número da revista Serrote, lançado em novembro de 2010 pelo Instituto Moreira Salles, há a tradução (feita por André Telles) de um texto de Maurice Blanchot: $O$ instante da minha morte, lançado originalmente em 1994. Foi o último relato publicado por Blanchot, que, a partir desse ano, expressou-se apenas por reuniões de fragmentos e textos circunstanciais de intervenção política. Colado ao texto de Blanchot, logo em seguida, como o vocábulo subsequente em uma frase que se forma, está um texto de Laurent Nunez intitulado Ao lado de Blanchot. O texto de Nunez comenta especialmente a relação de Jacques Derrida com Blanchot, e foi publicado no número 498 de Magazine Littéraire, de junho de 2010. Nunez segue em parte o que já havia apresentado em seu livro de 2006, Les écrivains contre l'écriture (1900-2000), no qual vasculha a relação entre a palavra e o silêncio - o silêncio peculiar da literatura, como afirma a epígrafe de O livro por vir - na obra não só de Maurice Blanchot, mas também de Paul Valéry, Georges Bataille, Antonin Artaud, Roger Caillois, entre outros.
O objetivo de Nunez é sublinhar o intenso contato entre Blanchot e Derrida, indicando, brevemente, como a obra do segundo assimilou elementos da obra do primeiro. Tudo começa com uma carta de Blanchot para Derrida, uma carta que inclusive podemos ver: está reproduzida em Serrote; vemos a caligrafia trêmula do ancião Blanchot. A carta, que não está datada (mas a informação bibliográfica é de que se trata de uma carta de 1995), tem 12 linhas e seu suporte é o verso de uma folha de fichário. Blanchot assina Maurice, usa uma caneta de tinta azul, possivelmente uma esferográfica. A tradução, apresentada no fim do artigo de Nunez, ficou da seguinte forma:

\section{Caro Jacques Derrida}

O livro? Ainda não, mas a amizade o precede.

E. Lev[inas], que não lê há anos, leu $O$ instante e fez comentários aprofundados. Que recompensa, me disse Michaël [Levinas]. Ele também falou do pas au-delà. Saiba que estarei sempre ao seu lado. Os que gostariam de me afastar de você não nos conhecem.

Escrevo com a insistência do que nos une.

$\mathrm{Na}$ fidelidade inexorável

Maurice (NUNEZ, 2010, p. 219) 
A carta de Blanchot foi reproduzida, em 2004, no Cahier de L'Herne dedicado a Derrida (número 83), iniciando a divulgação, ainda tímida, de uma troca ampla de correspondências entre os dois pensadores. Nunez afirma que Blanchot descobriu Derrida em 1963, por conta de um artigo publicado em Critique; afirma também que Derrida lia Blanchot desde o fim dos anos 1940. Há inclusive a indicação, dada por Roger Laporte a Nunez, de que Blanchot teria modificado alguns dos artigos posteriormente reunidos em $A$ conversa infinita depois de ter lido A escritura e a diferença, de Derrida. Blanchot, por sua vez, deu substância a muitos livros de Derrida, desde Políticas da amizade até o mais evidente Morada - Maurice Blanchot (no qual Derrida analisa justamente $O$ instante da minha morte). A presença de Blanchot é uma constante no desenvolvimento do pensamento francês da segunda metade do século XX, especialmente se lembrarmos as palavras de Didier Eribon, biógrafo de Michel Foucault:

Falando dos anos 50 Foucault diz um dia a Paul Veyne: 'Nessa época eu sonhava ser Blanchot', e conta-lhe que havia lido com paixão as crônicas que desde janeiro de 1953 o escritor publicara regularmente na Nouvelle Revue Française. Cabe assinalar que em outubro de 1953 Blanchot dedica um longo comentário a $O$ inominável de Samuel Beckett e analisa a dissolução do "eu" e do autor nesse texto. Foi talvez através de Blanchot que Foucault descobriu esse livro que cita com muita frequência: em sua aula inaugural no Collège de France, em 1970, por exemplo. Cita-o, entre aspas, mas sem mencionar o nome do autor. (ERIBON, 1990, p. 71-72)

A troca de cartas entre Blanchot e Derrida, portanto, ganha todo contorno filosófico que é possível para esse procedimento de contato, dada a repercussão dessa relação para o pensamento da contemporaneidade. É especialmente interessante pensar como a esfera privada, que remete à troca de informações acerca da vida cotidiana, termina por se mesclar à constituição de todo um sistema epistemológico, um sistema que define percursos de indivíduos muito distantes, seja no tempo ou no espaço (ou ambos), da cena inaugural. A carta de Blanchot é bem clara na demarcação que realiza: os que gostariam de me afastar de você não nos conhecem. Há um "nós", e há um "outros", "aqueles". O desejo de tomar por estranha uma conjunção que é declarada dá o ensejo para uma tomada de posição que é, também, crítica: não nos conhecem, ou seja, não leram o que escrevemos e, consequentemente, não leram aquilo que nós lemos. Ou ainda: é como se a fronteira que separa o geral do particular fosse suspensa, uma vez que Blanchot, de forma enigmática, encerra numa carta à Derrida uma diretriz que há de alimentar o debate público futuro.

\section{"Dor do diálogo"}

Essa tomada de posição é também aquela "dor do diálogo" de que fala Blanchot em O livro por vir antes da dor que encontramos nos diálogos escritos por Duras ou Malraux (que são os exemplos utilizados por Blanchot), a "dor do diálogo" é a dor do contato crítico, a dor da leitura, do entregar-se ao texto: "O crítico quase não lê", escreve Blanchot, o crítico "se simplifica, às vezes complicando, se louva, se condena, se ele se livra apressadamente da simplicidade do livro, substituindo-a pela retidão de um julgamento ou pela afirmação benevolente de sua rica compreensão" (BLANCHOT, 2005, p. 221). Trata-se, finalmente, de recuperar aquela insistência de que fala Blanchot na carta, essa insistência que os une, porque é nesse procedimento de reiteração (de ir e voltar, de retornar, de contornar) que se funda a crítica que está além da rica compreensão dona de si. Essa "benevolência" que encontramos na "dor do diálogo" de O livro por vir é própria "daqueles que não nos conhecem", uma vez que o movimento que marca esse "nós" é justamente a "insistência", a aposta de um pensamento que treme e que aceita seus tremores.

Essa articulação entre a troca privada de cartas e a definição de uma ética da leitura (que se revela a partir da leitura de Blanchot) não é estranha a Peter Sloterdijk, especialmente as considerações que faz em Regras para o parque humano. Segundo ele, pensar o humanismo e sua posição no atual estado de coisas é refletir sobre as comunidades que se formaram ao redor de métodos de leitura muito específicos. Para Sloterdijk, o humanismo sempre se locomoveu em torno da ideia de cooptação de sujeitos através de conceitos como o amor e a amizade. $\mathrm{E}$ nesse ponto Sloterdijk faz uso de uma palavra importante: a filosofia recruta seguidores ao falar de amor e de amizade (SLOTERDIJK, 2000, p. 7).

Primeiro de tudo, é importante ter em mente que o texto de Sloterdijk é a resposta a uma carta - também ele, esse texto de Sloterdijk, uma carta, já que se posiciona como um destinatário possível da missiva inicial. Trata-se da carta de Martin Heidegger sobre o humanismo, escrita em 1946 e motivada pela pergunta que o (à época) jovem filósofo francês Jean Beaufret havia lhe feito: "Como devolver um sentido à palavra 'humanismo'?". Beaufret requisitou Heidegger no imediato pós-guerra francês, procurando, dessa forma, consolidar para si um espaço proeminente no cenário acadêmico da época (lembremos da movimentação semelhante entre Blanchot e Derrida). No ano seguinte, 1947, Beaufret levou à Alemanha um 
grupo de alunos seus para terem aulas com Heidegger em Freiburg ${ }^{1}$.

Se pensarmos na repercussão da troca de cartas como o assentamento de uma base que permite um lançamento da obra ao futuro, é possível afirmar que esse foi um período fértil para Heidegger. Ainda em 1947, o filósofo alemão inicia contato com o psiquiatra suíço Medard Boss. A contribuição mútua se estenderá até, pelo menos, 1969, último ano das conferências que Heidegger apresentou em Zollikon, na Suíça. Heidegger e Boss trocaram centenas de cartas ao longo de décadas, consolidando, a partir disso, uma vertente de trabalho denominada daseinanalyse, que procura relacionar o pensamento sobre o patológico junto de uma reflexão acerca do ser no mundo e de sua liberdade ôntica (cf. HEIDEGGER, 2009). Por conta dessa troca de cartas, que refletia uma leitura atenta de Ser e tempo por parte de Boss (e uma aplicação especulativa em prática clínica), Heidegger partiu para a exposição do conteúdo de Ser e tempo para os alunos de Boss, dando ênfase a um imbricamento possível com a psiquiatra e a psicanálise.

Os encontros aconteciam na casa de Boss, e foi ele o responsável pela compilação do material e por sua posterior publicação, em 1987 (quarenta anos depois do contato de Heidegger tanto com Boss quanto com Jean Beaufret, portanto). O livro construído por Boss abarca não apenas as palavras de Heidegger, aquelas que efetivamente formaram seus seminários, mas também as cartas que trocaram, responsáveis, no fim das contas, por dar um norte às exposições de Heidegger. A apropriação feita por Medard Boss da obra de Heidegger caminha na direção de uma conceituação da convivência repercutindo na prática clínica. Contudo, não podemos iniciar uma reflexão sobre esse contato entre Boss e Heidegger sem mencionar, primeiro, dois outros nomes: Sigmund Freud e Ludwig Binswanger.

Boss, durante sua formação, foi analisando de Freud em fins da década de 1920, em Viena. Mais tarde, tornou-se colega de Carl Jung em Zurique, o que acentuou

\footnotetext{
1 Não posso deixar de assinalar o aparecimento de Jean Beaufret também no texto de Laurent Nunez, publicado em Serrote. A ocasião assinalada por Nunez é importante: ele diz que Blanchot e Derrida encontraram-se pela primeira vez em janeiro de 1968, por ocasião do "caso Beaufret". Consta que Beaufret foi acusado por Roger Laporte de proferir declarações antissemitas, e Derrida e Blanchot expressaram desconfiança publicamente com relação a Beaufret. O curioso é que, no ano anterior, 1967, os dois participaram de um livro em homenagem a Beaufret, do qual também participaram nomes como René Char, Michel Deguy e o próprio Laporte (sob a batuta de François Fédier). Segundo Christophe Bident, Beaufret teria dito as seguintes palavras na ocasião de uma eleição para um cargo na universidade de Clermont: "Si j'avais à choisir entre Clémence Ramnoux, X, Y, et un Juif, naturellement je voterais pour Clémence Ramnoux". Cf. BIDENT, Christophe. Maurice Blanchot: partenaire invisible. Seyssel: Champ Vallon, 1998, p. 463. A declaração foi negada, os intelectuais se reuniram, Derrida aventou a possibilidade de ser uma represália velada a Lévinas, a discussão girou em torno também do antissemitismo de Heidegger, e as relações nunca mais foram as mesmas.
}

sua tendência de procurar uma via alternativa ao ensino freudiano. Essa tendência já havia sido alimentada em seu contato com Binswanger, tanto pela circulação comum na Universidade de Zurique mas especialmente por conta da leitura de $O$ sonho e a existência, que Binswanger lança em 1930. Esse texto receberá um comentário de Michel Foucault em 1954, por conta da tradução ao francês. Foucault acrescenta ao livro um prefácio bastante longo, no qual elabora de forma pormenorizada os conceitos desenvolvidos por Binswanger (acrescentando suas próprias reflexões acerca do sonho e de sua linguagem). Foucault conhecia bastante bem o alemão, e ajudou Jacqueline Verdeaux (que pegou os originais diretamente das mãos de Binswanger, na visita que lhe fez em sua clínica em Kreuzlingen) com a tradução dos termos filosóficos. Novamente, Didier Eribon oferece informações interessantes:

\begin{abstract}
Jacqueline Verdeaux e Michel Foucault também vão várias vezes à Suíça para encontrar [Roland] Kuhn e Binswanger e mostrar-lhes as diferentes etapas da tradução em andamento. As discussões giram sobretudo em torno do léxico heideggeriano. Eles se interrogam durante horas para traduzir Dasein. No fim decidem falar simplesmente de 'presença', ao invés do habitual 'ser-no-mundo'. Concluída a tradução do texto de Binswanger, Jacqueline diz a Foucault: 'Se você gosta do livro, escreva o prefácio'. Ele não recua ante a dificuldade e logo se põe a escrever. (...) Os dois juntos vão procurar Binswanger para lhe mostrar o texto traduzido e o prefácio. O psiquiatra fica muito contente com ambos (ERIBON, 1990, p. 58-59).
\end{abstract}

É importante notar que a figura de Heidegger está sempre presente, desde Derrida e Blanchot, passando por Jean Beaufret e pela análise de Peter Sloterdijk, até chegar em Freud, Biswanger, Medard Boss e a elaboração foucaultiana - sem que esse percurso escape do raio de ação das palavras de Blanchot dirigidas a Derrida. No prefácio que escreve ao livro de Binswanger, Foucault afirma que "a psicanálise freudiana do sonho jamais é uma apreensão compreensiva do sentido", uma vez que "Freud fez habitar o mundo do imaginário pelo Desejo, tal como a metafísica clássica fizera habitar o mundo da física pelo querer e pelo entendimento divinos" (FOUCAULT, 2010, p. 77). Até certo ponto, Foucault rastreia o Heidegger que há na argumentação de Binswanger e, a partir disso, passa em revista os temas espinhosos da época em que escrevia: a dinâmica humanista no pós-guerra e a problematização intensa da formação metafísica da filosofia ocidental. É a partir desses pontos que podemos aproximar esse texto de início da carreira de Foucault com a carta que Heidegger havia escrito pouco tempo antes para Beaufret - que Sloterdijk interceptará bem mais adiante. 
É como se Foucault descolasse o sonho do sujeito que sonha, conferindo ao sonho uma imagem independente (mas não isolada) e, consequentemente, uma linguagem própria. Freud restituiu ao sonho, escreve Foucault (2010, p. 88), “uma dimensão psicológica; mas não soube conhecê-lo como forma específica de experiência". Ora, essa emancipação do sonho pretendida por Foucault é da ordem do pensamento pós-humanista, que repensa a centralidade do sujeito e certa antropologia que daí decorre. Foucault faz o sonho deslizar da esfera da análise psicológica para a esfera da teoria do conhecimento, afirmando que é exatamente esse o movimento de Binswanger em $O$ sonho e a existência. É importante notar que Foucault, nesse ponto, mostra que Binswanger "reatou laços" com uma tradição que remonta a Espinoza - o sonho, nessa tradição, é tomado como experiência imaginária, "cujo conteúdo [do sonho] designa o homem como ser transcendido" (FOUCAULT, 2010, p. 91). Foucault separa duas cartas de Espinoza para a corroboração desse trecho, uma delas para Hugo Boxel (de 1674), a outra para Pierre Bailling (1664), nas quais Espinoza apresenta um ponto de convergência entre uma tradição mística e um método racionalista, que desembocaria em uma significação híbrida do sonho.

\section{Regras para o parque humano}

Não é possível abandonar esse complexo pano de fundo quando nos detemos, por exemplo, nas reflexões de Peter Sloterdijk acerca da carta de Heidegger sobre o humanismo, em Regras para o parque humano. Solterdijk revisa não apenas o posicionamento de Heidegger diante do humanismo no pós-guerra; atravessa, também, todos esses momentos de assimilação diferida da obra de Heidegger. Quando lemos Sloterdijk hoje, estamos também lendo Jean Beaufret e Medard Boss, ainda que suas palavras não estejam ali, na página. Estamos entrando em contato com as comunidades que são formadas a partir desses textos, e a partir, principalmente, do procedimento das cartas. Trata-se, sobretudo, de uma lição blanchotiana: a filiação que se dá de forma subterrânea, o contato que exige trabalho para ser efetuado - trabalho do pensamento e também trabalho do tempo (também por isso o título que Derrida escolheu para seu livro sobre Blanchot: demeure, ou seja, local de suspensão e de atraso).

Sloterdijk aposta, também, no equívoco inerente a essa troca de cartas, ou seja, o equívoco que percorre todo movimento de reescrita dos textos - um movimento de apropriação que marca toda história da filosofia, que "prosseguiu sendo escrita como uma corrente de cartas ao longo das gerações, e, apesar de todos os erros de cópia, talvez até mesmo por causa desses erros, ela atraiu os copistas e intérpretes para seu círculo de amigos", escreve
Sloterdijk (2000, p. 7-8). O equívoco é produtivo quando se promove a retrospecção arqueológica do pensamento. Heidegger ocupou boa parte dos seminários de Zollikon mostrando os equívocos de Binswanger na apropriação em direção ao Dasein, por exemplo. A tentativa de substituir a categoria do cuidado pela categoria do amor foi negada por Heidegger. A ressalva,

não consiste tanto em que ele [Binswanger] quer complementar o 'cuidado' pelo amor, mas sim, no fato de que ele não vê que o cuidado tem um sentido existencial, isto é, ontológico, que a analítica do Dasein pergunta pela sua constituição fundamental ontológica e não quer simplesmente descrever fenômenos ônticos do Dasein. Já o projeto abrangente do ser-homem como Dasein no sentido ek-stático é ontológico, pelo qual a representação do ser-homem como 'subjetividade da consciência' é superada. Este projeto torna visível a compreensão do ser como constituição fundamental do Dasein (HEIDEGGER, 2009, p. 142).

A aproximação de Medard Boss permitiu a Heidegger revisar a leitura que Binswanger havia feito de sua obra, inaugurando, a partir disso, um desvio controlado em direção à daseinanalyse. Não estou interessado, evidentemente, em esmiuçar o que ficou de Heidegger nesse método clínico e de que forma ele conseguiu salvaguardar suas ideias a partir dos seminários de Zollikon. O que vale para a análise desenvolvida aqui é a atenção ao equívoco e essa exaltação da propriedade do texto de formar comunidades (seitas, sociedades secretas). A instauração do humanismo, para Sloterdijk, se dá na vontade de eliminar o equívoco, tornando claras as relações entre os homens e suas tradições: "É fácil entender por que as eras que tiveram suas experiências particulares com o potencial bárbaro que se libera nas interações de força entre os homens", escreve ele, "são justamente as épocas em que o chamado ao humanismo costuma ficar mais forte e mais premente" (SLOTERDIJK, 2000, p. 16). Está em jogo um desembrutecimento do ser humano, ou seja, a tarefa de fazê-lo ler corretamente, portar-se corretamente, enfim, ser corretamente.

A forma como esse cenário se plasma no texto é exposta por Foucault em um artigo de 1971 chamado "As monstruosidades da crítica". Trata-se de uma resposta de Foucault a duas críticas que havia recebido, uma de JeanMarie Pelorson e outra de George Steiner, a primeira sobre História da loucura, a segunda sobre As palavras e as coisas. A resposta de Foucault sai na Diacritics, em inglês, e reúne todos os pontos que foram levantados até aqui: o equívoco, a demarcação de uma amizade (ou inimizade) a partir da leitura, a dor do diálogo crítico e a revisão do humanismo. Tal como Blanchot havia escrito a Derrida sobre os "outros", aqueles que não nos conhecem, em "As monstruosidades da crítica" Foucault faz o mesmo 
movimento, pretendendo, com isso, excluir Steiner e Pelorson do círculo possível de sua obra. Foucault diz que "ambos obedecem às mesmas três leis (a ignorância do livro, a ignorância daquilo que eles falam, a ignorância dos fatos e dos textos que eles refutam)", chegando, no entanto, "a resultados diametralmente opostos: em um caso, trata-se de uma transformação que se efetua aumentando a entropia do livro; no outro, diminuindo-a" (FOUCAULT, 2006, p. 317).

Primeiro de tudo, há a questão da leitura: ao iniciar o artigo falando de Pelerson, Foucault é sarcástico, indicando, sutilmente, que tamanho absurdo só poderia ser escrito com a certeza de que ninguém o leria. Foucault, contudo, leu Pelerson e agora se posiciona diante desse texto "invisível", feito para ninguém, disposto a desmontar suas bases aparentemente frágeis. Foucault, assim como Heidegger diante de Binswanger (intermediado por Boss e seus alunos), atua como o vigilante de sua obra, como um guardião tenaz diante da porta da Lei que ele mesmo construiu: "A fim de poder criticá-lo [seu livro, História da loucura], o Sr. Pelorson inventa um livro no qual considera que os temas imaginários e as práticas reais são consideradas não distintas, e isso ao preço de um desconhecimento total do texto e das referências; assim, ele faz do livro uma variação sem regras de um mundo imaginário sans réalité" (FOUCAULT, 2006, p. 319). Foucault é incisivo, e parece ter um grande prazer (como em uma revanche) em chamar Pelorson de imbecil: "O Sr. Pelorson pensa que, quando se é colocado diante de um louco, sabe-se imediatamente que esse homem não é um imbecil, mas um louco. Pelo menos dessa vez", continua Foucault, "não estou longe de pensar a mesma coisa: há imbecis que reconhecemos imediatamente, quando os encontramos, que eles não são loucos, mas simplesmente imbecis" (2006, p. 321).

O tratamento dispensado a George Steiner não é diferente, mesmo considerando o fato de Steiner gozar de uma reputação muito maior do que a de Pelorson².

\footnotetext{
2 A crítica de Steiner a As palavras e as coisas saiu em fevereiro de 1971, no The New York Times Book Review. Coincidentemente, esse também foi o ano em que Steiner passou a receber sua Guggenheim fellowship, e, no mês seguinte, março de 1971, proferiu, na Universidade de Kent, a conferência que gerou o livro que conhecemos como No castelo do Barba Azul: algumas notas para a redefinição da cultura. Steiner escolheu como epígrafe para essa conferência um verso de René Char - poeta que também foi o escolhido, por Foucault, para a epígrafe do texto sobre Binswanger (isso os aproxima de uma forma estranha, não?). A essa altura, Steiner também já havia publicado seu estudo sobre Tolstoi e Dostoiévski (Tolstoy or Dostoevsky: An Essay in Contrast, de 1960), seu livro sobre a tragédia (The Death of Tragedy, de 1961) e sua célebre coletânea de ensaios, Language and Silence, de 1967. O título que Steiner deu à crítica já marca uma posição de antagonismo: "The mandarin of the hour: Michel Foucault", algo como "a sensação do momento", "a moda francesa mais recente", no sentido, também, de "embusteiro" ou "charlatão". O texto de Steiner pode ser lido no seguinte endereço eletrônico: $<$ http://www.nytimes.com/books/00/12/17/specials/ foucault-order.html>
}

Isso reflete no posicionamento de Foucault, que inicia sua vigilância de forma lisonjeira, afirmando que a resenha de Steiner é "muito mais sedutora, muito mais difícil e muito mais criativa" do que a de Pelorson, compartilhando, contudo, a mesma má-fé. Há um ponto que se repete: Foucault diz ser criticado por tudo aquilo que não disse, por todos os autores que não citou e todas os eventos históricos que não mencionou. Outro ponto que se repete: Foucault insiste na necessidade de se ler o que veio antes e o que veio depois, denunciando a "monstruosidade" das citações escolhidas pelos críticos - forçando a palavra de Foucault a servir em prol do "livro imaginário" que tanto Steiner quanto Pelorson criaram em suas resenhas. E o ponto mais forte: a ausência de contato com o texto, exatamente como Blanchot diagnosticou no trecho de O livro por vir citado mais acima (o crítico se livrando apressadamente da simplicidade do livro) - "O Sr. Steiner afirma que minha dívida é com Lovejoy, o que prova que ele não leu Daudin; ele afirma também que eu não cito minhas fontes, o que prova, uma vez mais, que ele não leu meu livro", escreve Foucault (2006, p. 324).

Essa preocupação com a leitura já está em Heidegger, conforme aponta Sloterdijk: "A carta ao jovem francês contém uma leve reprimenda ao inquiridor, que transparece claramente nas duas respostas imediatas" (SLOTERDIJK, 2000, p. 22). Ou seja, Sloterdijk chama a atenção para o fato de que Heidegger já começa sua carta sobre o humanismo (suscitada por um questionamento de Jean Beaufret e, posteriormente, destinada a ele) com uma correção de leitura, que é a seguinte: Beaufret, ao perguntar sobre um resíduo de sentido possível na palavra "humanismo", está levando-a adiante sem questionar a validade dessa continuidade; para Heidegger, "a palavra 'humanismo' deve ser abandonada se a genuína tarefa intelectual, que na tradição humanística ou metafísica pretende aparecer como já resolvida, tiver de ser novamente experimentada em sua simplicidade e inevitabilidade originais" (SLOTERDIJK, 2000, p. 23).

Sloterdijk mostra, a partir de Heidegger, que a filosofia está baseada no equívoco do humano, ou ainda, no equívoco da insistência do humano em colocar seus próprios padrões como explicação universal. Deve-se valorizar o humano a partir de um abandono completo de todas as premissas que ele levantou nos últimos dois mil anos. $\mathrm{O}$ grande erro estaria na definição do homem como um animal racional, ou seja, um ser eminentemente biológico, acrescido, no processo de sua definição, de uma porção de elementos espirituais. Para Heidegger, esse movimento configura uma subestimação do humano, e deve ser revisto - o humano deve, portanto, ser reconsiderado para além do humanismo; sua essência não deve ser definida a partir de um ponto de vista biológico ou zoológico. Essa é a postura de Heidegger 
tal como é mostrada por Sloterdijk em Regras para o parque humano, e ele registra essa passagem em palavras que retomam o que foi apontado, mais acima, como a vigilância tenaz do crítico diante de seu trabalho (de seu legado, de suas cartas): "Nesse ponto, Heidegger é inexorável, caminhando entre o animal e o ser humano como um anjo colérico com espada em riste para impedir qualquer comunhão ontológica entre ambos" (SLOTERDIJK, 2000, p. 25). Para Heidegger, essa diferença ontológica entre homem e animal se dá, também, por conta da inserção no mundo: enquanto o homem se liga a um mundo em expansão, articulado e complexo, ao animal está reservado o "ambiente", um espaço restrito, imutável. Heidegger, diz Sloterdijk, aposta na guarda do Dasein pelo homem - uma atividade de pastoreio que é possível apenas pela linguagem (definida como "a casa do ser"), por isso a radical divisão ontológica entre homem e animal ${ }^{3}$.

Esses são os últimos momentos de Heidegger na carta de Sloterdijk - uma carta que, aliás, tem uma estrutura muito peculiar: algumas páginas iniciais dando um panorama sobre o humanismo e a filosofia; logo depois a menção à troca de informações entre Jean Beufret $\mathrm{e}$ Martin Heidegger, seguida das páginas especificamente sobre Heidegger (não mais que 18); depois de Heidegger, Sloterdijk solicita Nietzsche e, finalizando, Platão (são exatas 10 páginas para cada um deles). Nesses últimos momentos, Sloterdijk volta à questão da amizade e da troca de saber como ingrediente para a formação de comunidades. Na leitura de Sloterdijk, Heidegger preservaria "a função mais importante do humanismo clássico", que é justamente a cooptação via amizade, ou ainda, "o estabelecimento de amizade do ser humano pela palavra do outro" (SLOTERDIJK, 2000, p. 27).

Esse procedimento (blanchotiano) de buscar a amizade a partir do conhecimento e, mais ainda, de reconhecer o sujeito como aquele que guarda o ser e, consequentemente, que guarda também o saber formado a partir desse ser (a tradição, a filosofia, as sociedades literárias), é, no caso de Heidegger, muito mais do que

\footnotetext{
3 Não será possível, aqui, entrar em detalhes com relação ao seminário de Jacques Derrida, A besta e o soberano, que se encaixa perfeitamente nesse interstício que se abre entre Heidegger e Sloterdijk. Mas adianto uma breve passagem, desenvolvida por Derrida ao longo do seminário, que apresenta os termos desse debate em uma ordem completamente distinta. Já na primeira sessão do seminário, de 12 de dezembro de 2001 , Derrida afirma: "En la intersección metamórfica de ambas figuras, la bestia y el soberano, presentimos pues que una profunda y esencial cópula ontológica está en marcha, trabajando esa pareja; es como un acoplamiento, una cópula ontológica, onto-zoo-antropo-teológicopolítica: la bestia se convierte en el soberano que se convierte em la biesta" Cf. DERRIDA, Jacques. Seminario La bestia y el soberano: volumen I: 2001-2002. Tradução para o espanhol de Cristina de Peretti e Delmiro Rocha. Buenos Aires, Manantial, 2010, p. 37. Se Heidegger andava de espada em riste na fronteira ontológica que separa o homem do animal, Derrida não apenas abre a fronteira, como estimula (teoricamente, epistemologicamente) essa "cópula", essa "cruza".
}

retórica. Vimos que no mesmo período de elaboração de sua carta, Heidegger estava em contato não só com Beaufret, mas também com Medard Boss - e vimos também a relevância desse contato para o desenvolvimento do pensamento heideggeriano, especialmente em seu contato com a leitura de Binswanger, que redundou, por sua vez, em uma leitura de Foucault.

A ultrapassagem do humanismo se daria, em Heidegger, a partir de uma inversão: se na tradição humanista, a formação intensiva (a leitura, a participação ativa na sociedade literária e a adaptação a certos modos canônicos de leitura) era o pré-requisito para a entrada na guarda do ser, agora o pré-requisito está dado de forma ontológica. Pelo fato de dominar a linguagem, o sujeito está confinado a essa casa que precisa guardarnão há formação que possa negar tal condição: "O autocontido habitar heideggeriano na casa da linguagem define-se como uma escuta paciente e às escondidas do que será dado ao próprio ser dizer", escreve Sloterdijk, e continua: "Invoca-se um estar-à-escuta-do-que-se-passaao-redor que deve tornar o ser humano mais quieto e mais domesticado que o humanista ao ler os clássicos" (2000, p. 28). Não é, portanto, a consciência empírica da biblioteca que leva o sujeito a guardar o ser (travar amizade, repartir o saber, constituir comunidades), e sim a consciência de sua formação ontológica própria (única, característica). "Com isso", escreve Sloterdijk (2000, p. 29):

Heidegger eleva o ser ao papel de autor exclusivo de todas as cartas essenciais e nomeia a si mesmo como seu presente relator. Quem fala a partir de tal posição pode também anotar balbucios e publicar silêncios. O ser envia, assim, as cartas cruciais; mais exatamente, ele faz acenos a amigos com presença de espírito, a vizinhos receptivos, a quietos pastores reunidos; contudo, tanto quanto podemos ver, nenhuma nação, e nem mesmo escolar alternativas, se formam do círculo desses co-pastores e amigos do ser - em boa medida porque não pode haver nenhum cânon público dos acenos do ser - a menos que deixássemos a opera omnia de Heidegger valer, até segunda ordem, como padrão e voz do super-autor anônimo.

O sujeito, portanto, não é dono de coisa alguma, não está de posse da linguagem nem daquilo que foi realizado por meio dela. Para além do humanismo, aponta Heidegger, está o homem que opera à margem do saber, tangenciando seus domínios, reafirmando constantemente a incompletude de sua tarefa. É preciso abandonar a ótica de um mundo construído a partir dos "homens fortes", investindo em um "exercício ontológico de humildade", buscando a "abençoada fraqueza" que indicaria a tarefa intelectual em tempos pós-humanistas (SLOTERDIJK, 2000, p. 30). 
Instaura-se, a partir daí, um cenário de combates - o gesto de cooptar amigos como a extensão do domínio da luta. Se tomarmos a carta de Heidegger como um marco possível para o pós-humano, veremos que cada uma das cenas delineadas até este ponto retoma essa posição de vigia diante de uma fronteira. Para Sloterdijk, Heidegger guarda a fronteira ontológica entre $\mathrm{o}$ homem e o animal tendo em mãos uma "espada em riste", e essa seria a cena inaugural quando procuramos problematizar esses momentos de definição de quem pode ou não participar de determinada troca simbólica. Heidegger, além de portar uma espada, é também comparado a um anjo - e nisso vemos como a construção política do presente está calcada em uma ideia teológica e belicista do ser. A própria ideia de um parque e de seu necessário conjunto de regras, por parte de Sloterdijk. Podemos lembrar, também, de como as declarações antissemitas de Jean Beaufret promoveram um ostracismo de ordem intelectual, especialmente por parte de Blanchot e Derrida, atentos que estavam a essa justaposição da política com a religião no pós-guerra. É como se, metonimicamente, as acusações contra Heidegger se transferissem ao pupilo francês.

\section{O cartão-postal}

Lado a lado com a formulação filosófica, portanto, está o cotidiano dos corpos, a influência inegável de uns sobre os outros e, principalmente, o cuidado com o texto que se transforma em legado. É isso que está no horizonte de um livro tão intenso quanto enigmático chamado $O$ cartão-postal: de Sócrates a Freud e além, publicado em 1980 por Jacques Derrida. Misto de revelação pessoal, memórias de viagem e comentário filosófico, O cartão-postal ataca diversas frentes, jogando com o lacunar, flertando com as etimologias, escandindo minuciosamente a tradição filosófica ocidental. Derrida toma a si mesmo como destinatário dessa tradição e, com o mesmo movimento, questiona não só a validade dessa encarnação, mas também a simples possibilidade de se declarar um "posto de passagem" - a vida do intelectual como uma central de triagem, como um monumento itinerante à porosidade, à mobilidade: "Vontade de escrever e, antes de tudo, de reunir uma enorme biblioteca sobre o correio", e também "as instituições postais, as técnicas e costumes da telecomunicação, as redes e as épocas da telecomunicação através da história", mas, escreve Derrida, “justamente a 'biblioteca' e a 'história' são apenas 'postos', lugares de passagem ou de albergues entre outros, estases, momentos ou efeitos de permanência" (DERRIDA, 2007, p. 35).
Derrida coloca a troca de cartas como problema filosófico e político - o mesmo movimento, aliás, de Heidegger e de Sloterdijk, pois é forçando para si um recebimento que se constrói um espaço possível dentro da tradição: "o leitor que se expõe a essa carta mais longa [a tradição] pode entender o livro como um convite, e, caso se entusiasme pela leitura, apresentar-se então ao círculo dos destinatários para lá dar testemunho do recebimento da mensagem" (SLOTERDIJK, 2000, p. 10). Além de colocar a troca de cartas como problema filosófico e político, Derrida coloca sua própria vida (suas viagens, suas inquietações, seu diário, literalmente) no centro dessa questão. O cartão-postal é um testemunho radical do recebimento da mensagem de que falava Sloterdijk.

$O$ cartão-postal interessa também na medida em que espelha um comportamento que foi demonstrado igualmente por Heidegger, que é justamente esse auto posicionamento no centro de uma cartografia do combate intelectual pós-humano. Em primeiro lugar, Sloterdijk (2000, p. 28-29) afirma que "Heidegger quer um homem mais servil do que o seria um mero leitor", uma vez que "seu desejo seria instituir um processo de estabelecimento de amizade no qual ele próprio não mais seria recebido apenas como um clássico ou um autor entre outros" - a meta de Heidegger é que o público "tomasse conhecimento de que, por intermédio dele, enquanto mentor da pergunta sobre o ser, o próprio ser tenha novamente começado a falar". Um mentor que, como vimos, não se compromete com a força ou com um destino reservado a um povo escolhido. Um mentor que se forma a partir de uma consciência intensamente trabalhada de proximidade com a "casa do ser", aquela que está sob sua responsabilidade. Encontramos essa postura tenaz, que envolve uma ética e uma responsabilidade (poder responder por, responder a, tomar posição, oferecer réplica) diante do que se diz, no texto de Foucault sobre as monstruosidades da crítica e nas palavras de Blanchot sobre a leitura apressada de certa crítica que prolifera. Voltamos a encontrar essa ética em $O$ cartão-postal.

Primeiro, são inúmeros os trechos em que Derrida mescla a vida cotidiana com os textos que lê, especialmente na primeira parte do livro, intitulada "Envios" (que ocupa metade do livro; a metade mais "livre", construída como um diário, com entradas organizadas a partir de datas: de 3 de junho de 1977 até 30 de agosto de 1979). Em 4 de maio de 1978, por exemplo, Derrida começa a entrada dizendo a seu destinatário invisível que "esse célebre museu se chama o Palácio dos Correios", e segue: "Logo que eu parar de mancar ("mas como diz a escritura, mancar não é um pecado", é a última palavra de Além..., a queda ou o envio), minha primeira visita será ao PP de Genebra" 
(DERRIDA, 2007, p. 158) ${ }^{4}$. Derrida está em Genebra, relendo Além do princípio do prazer, de Freud. Derrida manca e encontra sua condição peculiar nas linhas que relê.

Essa ideia do manquejar e do claudicar voltará mais adiante em $O$ cartão-postal, assim como outros elementos que Derrida deposita em "Envios" (a parte inicial, "biográfica") e vai resgatando nas partes posteriores do livro. Derrida está interessando em um duplo envio em direção a Freud: tornar-se ele mesmo destinatário de Freud e fazer, simultaneamente, com que o texto de Freud se volte sobre si mesmo, mostrando seus desvios e suas lacunas. É por isso que ele fala em ritmo - e para provar a eficácia desse estímulo crítico, dessa categoria, ele incorpora em seu próprio texto, largando pistas aqui e ali que o leitor costura ao final. Se o manquejar aparece no corpo de Derrida, é também porque foi lido em Além do princípio do prazer, que o envolve justamente por seu caráter especulativo - é para esse aspecto que Derrida chama a atenção: escutamos outro Freud, um Freud que fala de dentro da casa da família e, ao mesmo tempo, recorre a uma des-familiarização. Derrida, nesse ponto, volta à brincadeira do neto de Freud, Ernst, que fazia o carretel ir e voltar e exclamava: fort, $d a$.

Esse é também o envio de que fala Derrida: a criança com o carretel na mão, o olhar de Freud sobre a cena que se repete, a experiência familiar que se torna especulação metapsicológica, a cena doméstica que se transforma no texto intrincado, denso, manco, que é justamente Além do principio do prazer. Derrida escreve (DERRIDA, 2007, p. 159): "Releio Além... cuidadosamente (tudo é maravilhosamente hermético ali, ou seja, postal e monótono - subterraneamente ferroviário, mas também

\footnotetext{
4 Derrida não deixa claro se sua leitura de Freud se dá no original em alemão e se a citação acompanha alguma tradução ao francês do texto de Freud. O fato é que ao ler a citação de Freud em português no livro de Derrida estamos diante de uma série de camadas tradutórias. A edição recente de Freud no Brasil, com tradução de Paulo César de Souza, apresenta a citação da seguinte forma: "O que não podemos alcançar voando, devemos alcançar claudicando. [...] Segundo as Escrituras, não é pecado claudicar." Cf. FREUD, Sigmund. "Além do princípio do prazer" In: História de uma neurose infantil: ("O homem dos lobos"): além do princípio do prazer e outros textos (1917-1920). Tradução e notas de Paulo César de Souza. São Paulo: Companhia das Letras, 2010, p. 239. Trata-se da citação de um dos sermões do escritor árabe $A b u$ Hariri, que Freud cita a partir da tradução de Friedrich Rückert (o que não deixa de ser curioso, tendo em vista as origens magrebinas de Derrida, além de balançar a primeira impressão dada pela palavra "Escrituras", que, na citação de Derrida em seu diário, não ganha especificação). É interessante notar também o aspecto mais literal de "mancar" com relação a "claudicar", já que o primeiro termo parece levar em consideração uma perturbação morfológica e funcional do corpo humano. Segundo Carlo Ginzburg, há uma intensa relação entre o manquejar e o contato com outros mundos, através, principalmente, de experiências extáticas. O manquejar seria a marca deixada no corpo por essa experiência radical de troca de saberes. Cf. GINZBURG, Carlo. História noturna: decifrando o Sabá. Tradução de Nilson Moulin. São Paulo: Companhia das Letras, 1991. E também ANDERSON, Perry. "Investigação noturna: Carlo Ginzburg” In: Zona de compromisso. Tradução de Raul Fiker. São Paulo: Editora da Universidade Estadual Paulista, 1996. Seria interessante investigar a sobrevivência dessas cenas e figuras mitológicas na retórica de pesquisadores contemporâneos das ciências humanas.
}

manco, coxo: ele não nos diz NADA, não dá um passo que não retire no passo seguinte". Colocando-se diante de Além..., buscando dele novas coisas (agindo como aquele filósofo de que fala Sloterdijk, que se posta diante do texto como se fosse uma carta pessoal, dirigida unicamente a ele), Derrida envia a Freud seu próprio texto, e procura emular, em $O$ cartão-postal, o mesmo atravessamento entre familiaridade e especulação filosófica de Além.... É por isso que o mesmo livro contém um diário ("Envios") e uma série de seminários, um deles sintomaticamente intitulado "Legados de Freud".

Mais adiante, no trecho do livro que já não é mais um diário, que se forma como uma argumentação teórica mais coesa, Derrida escreve que vê Além... "no caminho singular da especulação", especialmente no trecho em que Freud fala das neuroses de destino, nas quais se encontra uma repetição com "os traços do demoníaco" - "O fantasma do demoníaco, na verdade do diabólico, reaparece a intervalos regulares no Além...”, anota Derrida (2007, p. 297). Vale a pena ressaltar a atenção de Derrida sobre o reaparecimento, sua leitura dos "intervalos regulares" de Freud, que marcam o ritmo de sua escrita, que marcam, principalmente, a cadência de seus ensinamentos e o envio que está em jogo. Pois é essa cadência que será o foco do trabalho de Derrida, não apenas em $O$ cartão-postal, mas em todos os textos posteriores que continuarão perseguindo Além do princípio do prazer. É na oscilação desses intervalos que Derrida posiciona seu próprio trabalho, enviando suas próprias cartas e requisitando seus próprios espaços de circulação ${ }^{5}$.

É da natureza deste trabalho mancar - ou seja, claudicar, oscilar, flertar com o inconcluso. Derrida

\begin{abstract}
Ainda no trecho inicial de $O$ cartão-postal ("Envios"), Derrida faz uma aproximação reveladora entre Freud e Heidegger, oferecendo material muito produtivo para a discussão que estou esboçando neste texto. Ele escreve: "Aqui Freud e Heidegger, eu os conjugeio [as tradutoras escolheram essa palavra para resolver o neologismo conjoins, criado por Derrida a partir do termo conjoint, que aponta para "junto" e "cônjuge"] em mim como os dois grandes fantasmas da 'grande época'. Os dois avôs sobreviventes. Eles não se conheceram mas formam em minha opinião um casal, justamente por causa disso, dessa singular anacronia. Eles se ligam sem se ler e sem se corresponder. Eu falei a você frequentemente dessa situação e é essa imagem que eu gostaria de descrever em $O$ legado: dois pensadores que nunca cruzaram um olhar e que, sem nunca receber uma única palavra do outro, dizem a mesma coisa. Eles estão dirigidos para o mesmo lado. Os mestres-pensadores são também mestres de correio. Saber ser hábil com a posta-restante. Saber não estar ali e ser forte para não estar ali imediatamente. Não entregar sob encomenda, saber esperar e fazer esperar, durante tanto tempo quanto exige o que há em si de mais forte - e até morrer sem nada dominar da destinação final" Cf. DERRIDA, 2007, p. 215. Os elementos que podem ser desdobrados a partir dessa citação são inúmeros: os "avôs sobreviventes" dá a medida da proximidade familiar que Derrida dedica a ambos (e que encontramos mais adiante também com Blanchot); a produção de uma confluência entre Freud e Heidegger por parte de Derrida, ou seja, é na decisão de sua obra que esse encontro acontece; o "dizer a mesma coisa" como indicação de um esforço de leitura, mais do que uma especulação acerca do momento da produção, seja de Freud, seja de Heidegger; o pensamento como uma atividade postal, algo que envolve um saber enviar e um saber esperar, uma atenção para o tempo próprio do trabalho intelectual, que não "entrega sob encomenda", mas que força seu próprio caminho.
\end{abstract}


coloca-se como receptor de Além... exatamente porque o vê como o livro mais especulativo de Freud, aquele que lhe dá mais possibilidades de trabalho. "A própria marcha do texto é diabólica", escreve Derrida; "Diabo manco, tudo o que transgride o princípio do prazer sem jamais permitir que se conclua uma travessia", e mais: "Manco, o diabo, porém absolvido de não se sabe qual dívida por aquele que num dado momento se diz 'advocatus diaboli' da pulsão de morte e conclui com uma citação na qual cada palavra se deixa remarcar como Escritura - e como literatura" (DERRIDA, 2007, p. 298), e nesse ponto Derrida repete o trecho final de Além..., que já havia citado em seu diário.

\section{Conclusão}

Há, portanto, para Derrida, um diabo operando na escritura de Além..., um diabo que leva Freud à escritura e que também escreve em seu lugar, permanecendo, no entanto, ausente, invisível - forçando o dito até o ponto no qual ele se abandona, expondo-se. Esse diabo interfere também no envio que Freud realiza de seu livro, e essa alteração só pode ser observada com o tempo, ou melhor, quando a leitura fica inchada de tempo, carregada de tempo. É nesse sentido que o manquejar é produtivo para Derrida: interessa mais a comunidade que se forma a partir do detalhe revelador, da minúcia encoberta, do que aquela que se desenvolve sob a sombra generosa das associações clássicas e canônicas. Nas palavras de Derrida, oúltimo capítulo de Além... (e também Além... considerado como um capítulo dentro da produção total de Freud), aquele que fala do manquejar, funcionaria como "uma espécie de membro atrofiado ou de pé torto", somente para afirmar na abertura do parágrafo seguinte: "Não se passa algo com esse membro curto ou com esse pé torto? Algo marcha com ele?" (DERRIDA, 2007, p. 434). Derrida reconhece a produtividade de um abandono, a possibilidade de extrair sentido de um trecho aparentemente desleixado, manco, atrofiado.

É no manquejar, segundo a lição de Blanchot aproveitada intensamente por Derrida, que se revela a atividade crítica trabalhosa, aquela que transcende a comunidade "benevolente" e alcança a comunidade dos "insistentes" ("escrevo com a insistência que nos une", escreve Blanchot a Derrida). Meu percurso neste ensaio tentou mostrar algumas das reverberações possíveis daquela "fidelidade inexorável" de que também fala Blanchot na carta a Derrida (NUNEZ, 2010, p. 219). De Blanchot até Derrida, Heidegger ou Foucault, o que está em jogo é o procedimento de transmissão do pensamento. Com a entrada em cena da carta e da correspondência, inaugura-se uma concepção disruptiva do contato possível entre ideias e suas respectivas temporalidades, uma concepção que foge do olhar que "se livra apressadamente da simplicidade do livro, substituindo-a pela retidão de um julgamento ou pela afirmação benevolente de sua rica compreensão" (BLANCHOT, 2005, p. 221). O livro, para Blanchot, era toda a tradição do pensamento filosófico e toda a história da literatura, condensadas em um substrato aberto à intervenção e às manobras do pensador sensível. Uma tarefa que se traveste de privilégio - e que solicita o posicionamento de todo aquele que, diante do contemporâneo, revisita a escritura de Maurice Blanchot e suas sobrevivências.

\section{Referências}

ANDERSON, Perry. Investigação noturna: Carlo Ginzburg. Zona de compromisso. Tradução de Raul Fiker. São Paulo: Editora da Universidade Estadual Paulista, 1996. p. 67-98.

BIDENT, Christophe. Maurice Blanchot: partenaire invisible. Seyssel: Champ Vallon, 1998.

BLANCHOT, Maurice. O livro por vir. Tradução de Leyla Perrone-Moisés. São Paulo: Martins Fontes, 2005.

DERRIDA, Jacques. Seminario La bestia y el soberano: volumen I: 2001-2002. Tradução para o espanhol de Cristina de Peretti e Delmiro Rocha. Buenos Aires: Manantial, 2010.

DERRIDA, Jacques. O cartão-postal: de Sócrates a Freud e além. Tradução de Simone Perelson e Ana Valéria Lessa. Rio de Janeiro: Civilização Brasileira, 2007.

ERIBON, Didier. Michel Foucault, 1926-1984. Tradução de Hildegard Feist. São Paulo: Companhia das Letras, 1990.

FOUCAULT, Michel. Introdução (in Binswanger). In: MOTTA, Manoel Barros da (Org.). Problematização do sujeito: psicologia, psiquiatria, psicanálise. Tradução de Vera Lucia Avellar Ribeiro. Rio de Janeiro: Forense Universitária, 2010. p. 71-132.

FOUCAULT, Michel. As monstruosidades da crítica. In: MOTTA, Manoel Barros da (Org.). Estética: literatura e pintura, música e cinema. Tradução de Inês Autran Dourado Barbosa. Rio de Janeiro: Forense Universitária, 2006, p. 316-325.

FREUD, Sigmund. Além do princípio do prazer. História de uma neurose infantil: ("O homem dos lobos"): além do princípio do prazer e outros textos (1917-1920). Tradução e notas de Paulo César de Souza. São Paulo: Companhia das Letras, 2010, p. 161-239.

GINZBURG, Carlo. História noturna: decifrando o Sabá. Tradução de Nilson Moulin. São Paulo: Companhia das Letras, 1991.

HEIDEGGER, Martin. Seminários de Zollikon: protocolos, diálogos, cartas. Tradução de Gabriela Arnhold e Maria de Fátima de Almeida Prado. Petrópolis: Vozes, 2009.

NUNEZ, Laurent. Les écrivains contre l'écriture. Paris: José Corti, 2006.

NUNEZ, Laurent. Ao lado de Blanchot. Serrote, São Paulo, n. 6, p. 213-219, nov. 2010.

SLOTERDIJK, Peter. Regras para o parque humano: uma resposta à carta de Heidegger sobre o humanismo. Tradução de José Oscar de Almeida Marques. São Paulo: Estação Liberdade, 2000.

Recebido: 10 de fevereiro de 2015

Aprovado: 14 de agosto de 2015

Contato: kelvin.klein@gmail.com 